\title{
PENGARUH KOMITMEN ORGANISASI DAN PENGENDALIAN INTERNAL TERHADAP RESIKO TERJADINYA KECURANGAN (FRAUD) DALAM PELAKSANAAN JAMINAN KESEHATAN DI RUMAH SAKIT BHAYANGKARA TK. IV POLDA SULUT
}

\author{
Toisuta Novenia Natasya ${ }^{1}$, Herman Karamoy $^{2}$, Robert Lambey ${ }^{3}$ \\ ${ }^{1,2,3}$ Fakultas Ekonomi dan Bisnis, Jurusan Akuntansi, Universitas Sam Ratulangi, Jl. Kampus Bahu, Manado, \\ 95115, Indonesia
}

E-mail : ntoisuta@yahoo.co.id

\begin{abstract}
Fraud is an action that is often found in various organizations or agencies. By instilling a high sense of organizational commitment to each individual as well as the establishment and implementation of internal controls, it is hoped that it will create a barrier to the misuse by public servants, especially in the field of health such as doctors and other paramedics in the implementation of health insurance. This research was aimed to determine the risk of fraud in the implementation of health insurance. The population of this research is all employees who work in hospital Bhayangkara TK..IV Polda Sulut. This study used multiple linear regression method with the help of spss. The results of hypothesis shown that the organizational commitment has no significant impact on fraud risk. Internal control give the significant impact to the risk of fraud.
\end{abstract}

Keywords: Fraud, Organizational Commitment, Internal Control

\section{PENDAHULUAN}

Rumah sakit merupakan salah satu jaringan pelayanan kesehatan yang penting, sarat dengan tugas, beban, masalah dan harapan yang diberikan kepadanya. Kegiatan utama sebuah rumah sakit adalah memberikan pelayanan kesehatan yang maksimal kepada pasien. Memberikan pelayanan yang baik serta dimilikinya instrumen organisasi yang handal menjadikan rumah sakit tetap bertahan sebagai pelayanan publik merupakan tuntutan yang harus dipenuhi. Hal ini merupakan isu yang penting karena rumah sakit merupakan pusat pertanggungjawaban yang bertanggungjawab terhadap pelayanan kesehatan masyarakat, sehingga pelayanan kesehatan yang diterima masyarakat dapat terjangkau dan berkualitas.

Rumah sakit sebagai entitas pelayanan umum tetap dituntut untuk tetap bertahan dan memperlihatkan kinerjanya dengan baik, dimana kondisi krisis global memberikan dampak pada hampir seluruh sektor perekonomian, termasuk rumah sakit. Pengelolaan rumah sakit yang baik tentunya akan memberikan acuan ataupun gambaran bagaimana rumah sakit terkelola secara transparan, mandiri, akuntabel, bertanggungjawab dan wajar sehingga kinerja keuangan pada rumah sakit dapat dicapai sesuai dengan visi dan misi rumah sakit yang telah ditentukan sebelumnya, namun demikian harapan di atas belum sepenuhnya dapat dirasakan. Hal ini disebabkan karena belum memadainya instrumen organisasi untuk menciptakan pengelolaan yang baik dan belum terbangunnya komitmen yang tinggi dari para pengelola rumah sakit. Akibatnya muncul berbagai penyimpangan, penyelewengan, penyelundupan dan korupsi. Fenomena fraud menjadi sesuatu yang lumrah di rumah sakit. Intensitas pembicaraan mengenai fraud di Rumah Sakit semakin tinggi, sama halnya yang terjadi di sektor publik lainnya, utamanya sektor pemerintah yang menangani masalah pelayanan umum pada masyarakat. Sebenarnya niat pemerintah mulai terlihat dan memperhatikan program untuk mengeliminasi fraud yang dilakukan oleh aparat pemerintahan. Hal ini diindikasikan dengan peningkatan peran Komisi Pemberantasan Korupsi (KPK), kejaksaan, kepolisian, atau pengadilan Tindak Pidana Korupsi atau koruptor (Tipikor). Namun 
sayangnya, hal ini sepertinya belum menjadi semacam komitmen untuk dijalankan secara bersama-sama secara konsisten di semua lini.

Pihak- pihak yang melakukan fraud adalah peserta (pasien), pemberi pelayanan kesehatan (provider), perusahaan asuransi (payer)(Ginting dalam Sadikin Hasan dan Wiku Adisasmito 2016:29). Melihat definisi di atas, dapat diindikasikan bahwa tindakan fraud merupakan unsur kesengajaan dan tindakan merugikan pihaklain dari pelaku sehingga UU Pidana bisa diberlakukan.Pada dasarnya, Jaminan Kesehatan Nasional (JKN) memberikan manfaat yang bersifat komprehensif (Thabrany dalam Sadikin Hasan dan Wiku Adisasmito 2016:29). Dibalik tujuan mulia JKN, potensi fraud yang mungkin terjadi perlu diidentifikasi sehingga tidak akan menimbulkan kerugian uang negara (Wiyono dalam Sadikin Hasan dan Wiku Adisasmito 2016:29). Padahal pengembangan sistem kesehatan di suatu Negara pada dasarnya untuk mencapai kondisi derajat kesehatan yang baik (WHO dalam Sadikin Hasan dan Wiku Adisasmito 2016:29).

Robin \& Judge dalam Ni Putu Sri Widiutami (2017:6), mendefinisikan komitmen sebagai suatu keadaaan dimana seorang individu memihak organisasi serta tujuan-tujuan dan keinginannya untuk mempertahankan keanggotaanya dalam organisasi. Semakin tinggi komitmen pegawai terhadap organisasi, pegawai tersebut cenderung tidak akan melakukan hal-hal yang bisa saja menghambat tercapainya tujuan organisasi. Sebaliknya, jika pegawai memiliki komitmen yang rendah terhadap organisasinya, maka pegawai cenderung akan melakukan hal-hal yang menghambat tercapainya tujuan organisasi demi tujuan pribadinya sendiri (Najahninggrum dalam Ni Putu Sri Widiutami 2017:6), Salah satu tindakan tersebut adalah kecurangan. Pegawai tersebut akan merasionalisasi tindakannya dikarenakan pegawai tersebut penerimaan yang baik atas nilai-nilai dan tujuan organisasi. Jika pengendalian internal suatu perusahaan lemah maka kemungkinan terjadinya kesalahan dan fraud sangat besar. Sebaliknya, jika pengendalian internal kuat, maka kemungkinan terjadinya kesalahan dan fraud dapat diperkecil. Kalaupun kesalahan dan fraud masih terjadi, bisa diketahui dengan cepat dan dapat segera diambil tindakan-tindakan perbaikan sedini mungkin.

Pengendalian internal yang efektif dapat melindungi pencurian, penggelapan, penyalahgunaan aktiva pada lokasi yang tidak tepat (Karyono, 2013:96). Selain itu, pengendalian internal juga memberikan jaminan yang wajar terhadap informasi bisnis yang akurat demi keberhasilan perusahaan. Penjagaan aktiva dan aktiva yang akurat sering berjalan seiring, karena karyawan yang ingin menggelapkan aktiva atau berniat melakukan kecurangan juga perlu menutupi kecurangan tersebut dengan menyesuaikan catatan akuntansi. Pengendalian internal dirancang untuk dapat mengamankan harta milik organisasi, bila pengendalian internal tidak dapat berfungsi efektif sebagai sarana kendali, kemungkinan besar terjadi fraud.

Penyidik KPK mengungkapkan, lemahnya pengendalian internal dalam sebuah organisasi membuka peluang untuk melakukan fraud (Herda Helmjaya dalam Ni Putu Sri Widiutami 2017:5,). Sistem pengendalian yang buruk akan memicu seseorang melakukan perbuatan fraud dan melawan hukum. Menurut Arens dalam Ni Putu Sri Widiutami (2017:5), pengendalian internal meliputi lima kategori pengendalian, yaitu (1) lingkungan kendali, (2) penilaian resiko, (3) aktivitas pengendalian, (4) informasi dan komunikasi, dan (5) pengawasan. Keefektifan pengendalian internal dalam organisasi dapat mencegah dan mendeteksi kecurangan. Adanya pengendalian internal maka pengecekan akan terjadi secara otomatis terhadap pekerjaan seseorang oleh orang lain. Kesesuaian pengendalian intern berpengaruh terhadap terjadinya kecurangan (Thoyibatun, dalam Ni Putu Sri Widiutami 2017:5). Selain pengendalian internal yang diterapkan sebagai salah satu tindakan preventif dalam mengetahui resiko terjadinya fraud(kecurangan), maka salah hal yang mungkin dapat meminimalisir fraud(kecurangan) tersebut salah satunya adalah komitmen organisasi. Dalam hal ini, komitmen organisasi adalah keinginan pelaku sosial untuk memberikan tenaga dan 
loyalitasnya pada sistem sosial, keterkaitan seseorang terhadap hubungan sosial dimana ia dapat mengekspresikan diri.

\section{TINJAUAN PUSTAKA}

\subsection{Akuntansi}

Menurut Accounting Principles Board dalam Sodikin (2014:1) akuntansi adalah suatu kegiatan jasa. Funsinya adalah untuk menyediakan informasi kuantitatif, terutama yang bersifat keuangan, tentang entitas ekonomik yang dimaksudkan agar berguna dalam pengambilan keputusan ekonomik, dalam mengambil pilihan-pilihan beralasan diantara pelbagai tindakan alternatif. Akuntansi meliputi beberapa cabang misalnya, akuntansi keuangan, akuntansi manajemen, dan akuntansi pemerintahan. Menurut definisi di atas, akuntansi berfungsi sebagai penyedia informasi kuantitatif, terutama yang bersifat keuangan. Informasi tersebut diharapkan dapat menjadi masukan dalam proses pengambilan keputusan ekonomik dan rasional.

\subsection{Akuntansi Manajemen}

Menurut Sodikin (2014:3) Akuntansi manajemen menyediakan informasi untuk kepentingan pihak internal entitas ekonomik, yaitu manajemen yang berfungsi mengelola perusahaan. Menurut Hansen (2015:4) Akuntansi Manajemen tidak terikat oleh kriteria formal apapun yang mendefinisikan sifat dari proses, masukan, atau keluarannya .

\subsection{Komitmen Organisasi}

Porter, Mowday dan Steers dalam Anggit Purwitasari (2013:19) mendefinisikan komitmen organisasi yaitu:

"For purposes of instrument development, organizational commitment was defined here as the relative strength of an individual's identification with and involvement in a particular organization (Porter \& Smith, Note 4). It can be characterized by at least three related factors: (1) a strong belief in and acceptance of the organization's goals and values; (2) a willingness to exert considerable effort on behalf of the organization; and (3) a strong desire to maintain membership in the organization."

\subsection{Pengendalian Internal}

Struktur pengendalian intern merupakan istilah yang telah umum dan banyak digunakan dalam berbagai kepentingan. Istilah pengendalian intern diambil dari terjemahan istilah "Internal Control". Menurut Drs. Amin Widjaya Tunggal (2014) "Pengendalian internal adalah suatu proses yang dijalankan oleh dewan komisaris, manajemen, dan personal lain dari suatu entitas yang didesain untuk memberikan keyakinan memadai tentang pencapaian golongan tujuan berikut ini: (a) efektivitas dan efisiendi operasi, (b)keandalan pelaporan keuangan dan (c) kepatuhan terhadap hukum dan peraturan yang berlaku".

\subsection{Fraud (Kecurangan)}

Definisi Fraud menurut Karyono (2013:4-5) fraud dapat diistilahkan sebagai kecurangan yang mengandung makna suatu penyimpangan dan perbuatan melanggar hukum (illegal act), yang dilakukan dengan sengaja untuk tujuan tertentu misalnya menipu atau memberikan gambaran keliru (mislead) kepada pihak-pihak lain, yang dilakukan oleh orangorang baik dari dalam maupun dari luar organisasi. Kecurangan di rancang untuk memanfaatkan peluang-peluang secara tidak jujur, yang secara langsung maupun tidak langsung merugikan pihak lain." 


\subsection{Jaminan Kesehatan}

Dijaman serba modern seperti saat ini semuanya menjadi serba mahal, dan salah satunya adalah mahalnya biaya pengobatan. Namun dibalik modernisasi tersebut, walaupun serba mahal namun semuanya menjadi begitu mudah dan praktis. Dalam dunia kesehatan sendiri, tidak perlu dipungkiri bahwa semuanya juga semakin mahal, biaya pengobatan, perawatan, dan lainnya semuanya semakin mahal.

\subsection{Kecurangan terhadap Jaminan Kesehatan}

Sejak 1 Januari 2014 program Jaminan Kesehatan Nasional (JKN) sebagai salah satu program dalam Sistem Jaminan Sosial Nasional pemerintah yang bertujuan mulia mulai diimplemntasikan. Dan sekarang berjalan, tentunya dalam proses implementasinya dilakukan perbaikan dan koreksi disana sini guna Program JKN bisa diterima oleh penduduk Indonesia dengan cita rasa kepuasan yang memuaskan sebagai salah satu indikator mutu layanan yang diselenggarakan oleh Badan Penyelenggara Jaminan Sosial (BPJS) bidang kesehatan

\subsection{Penelitian Terdahulu}

Anggita Purwitasari (2013) dalam penelitian berjudul Pengaruh Pengendalian Internal dan Komitmen Organisasi dalam pencegahan fraud pengadaan barang. Hasil penelitian menunjukkan bahwa Pengendalian internal dan komitmen organisasi berpengaruh secara signifikan terhadap pencegahan fraud. Marlina, Indah Lia Puspita dan Eka Sariningsih (2012) dalam penelitian berjudul Penerapan sitem pengendalian intern terhadap resiko terjadinya kecurangan (fraud) dalm pengadaan obat-obatan di instalasi farmasi dan sistribus obat-obatan kepada pasien. Hasil penelitian menunjukkan bahwa Penerapan SPI belum memenuhi beberapa komponen pengendalaian intern sehingga dapat dikatanbelum dapat mencegah terjadinya peluang dan kesempatan kecurangan.

\subsection{Kerangka Pemikiran}

Kerangka pemikiran adalah suatu tinjauan mengenai apa yang diteliti dan dituangkan dalam sebuah bagan yang menjadi alur pemikiran penelitian kerangka pemikiran dari penelitian ini. Rumah sakit merupakan salah satu jaringan pelayanan kesehatan yang penting, sarat dengan tugas, beban, masalah dan harapan yang diberikan kepadanya. Kegiatan utama sebuah rumah sakit adalah memberikan pelayanan kesehatan yang maksimal kepada pasien. Sebagai suatu entitas pelayanan kesehatan terhadap masyarakat, diperlukan suatu pemahaman mengenai pengendalian internal yang akan diterapkan oleh tenaga paramedis di rumah sakit, dimana jika hal ini diterapkan secara efektif maka dapat mengetahui resiko terjadinya fraud (kecurangan).

\subsection{Hipotesis Penelitian}

\subsubsection{Pengaruh Komitmen Organisasi dengan Resiko Fraud Pelaksanaan Jaminan Kesehatan}

Hubungan antara komitmen organisasi dengan pencegahan fraud sangat berkaitan. Dengan adanya komitmen organisasi dalam sebuah perusahaan dipercaya dapat bermanfaat dalam hal membantu perusahaan dalam mendeteksi resiko dan mencegah terjadinya fraud. Pada dasarnya komitmen b manajemen dan kebijakan suatu instansi/organisasi merupakan kunci utama dalam mencegah dan mendeteksi fraud.

\subsubsection{Pengaruh Pengendalian Internal dalam Resiko Fraud Pelaksanaan Jaminan Kesehatan}


Hubungan antara pengendalian internal dengan masalah kecurangan dalam suatu perusahaan sangat berkaitan. Kecurangan selalu menjadi isu yang sulit. Pengimplementasian dari pengendalian intern setidaknya dapat mengurangi kolusi manajemen mengenai fraud.

\section{METODE PENELITIAN}

\subsection{Jenis Penelitian}

Jenis penelitian yang akan dilakukan merupakan penelitian deskriptif kuantitatif.

\subsection{Tempat Dan Waktu Penelitian}

Rumah Sakit Bhayangkara TK.IV Polda Sulut. Dengan permasalahan yang diankat dari penelitian ini, maka lamanya waktu penelitian dari bulan Juli-Agustus.

\subsection{Prosedur Penelitian}

1. Survei Pendahuluan

2. Identifikasi Objek

3. Pengumpulan Data

4. Analisa Data

5. Hasil Penelitian

6. Kesimpulan dan Saran

\subsection{Populasi dan Sampel}

\subsubsection{Populasi Penelitian}

Populasi adalah wilayah generalisasi yang terdiri atas obyek/subyek yang mempunyai kualitas dan karakteristik tertentu yang ditetapkan oleh peneliti untuk dipelajari dan kemudian ditarik kesimpulannya (Sugiyono, 2014:115). Populasi dalam penelitian ini adalah karyawan dan tenaga medis yang berada di Rumah Sakit Bhayangkara TK.IV Polda Sulut yang berjumlah 178 orang.

\subsubsection{Sampel Penelitian}

Definisi sampel menurut Sugiyono (2014: 116) yaitu: "Sampel adalah bagian dari jumlah dan karakteristik yang dimiliki oleh populasi tersebut.”

\subsection{Metode Pengumpulan Data}

\subsubsection{Jenis Data}

Jenis data dalam penelitian ini yaitu data kuantitatif yang berupa nilai atau skor atas jawaban yang diberikan oleh responden terhadap pertanyaan-pertanyaan yang terdapat dalam kuesioner.

\subsubsection{Sumber Data}

Sumber data yang digunakan dalam penelitian ini adalah data primer yang secara langsung bersumber dari responden tanpa ada perantara, dalam hal ini adalah jawaban atas pertanyaan-pertanyaan yang ada dalam kuesioner. Data primer yang dihasilkan dalam penelitian ini adalah merupakan hasil dari tanggapan responden terhadap variabel-variabel penelitian yang akan diuji. Sumber data penelitian ini adalah karyawan dan tenaga medis Rumah Sakit Bhayangkara TK.IV Polda Sulut.

\subsubsection{Teknik Pengumpulan Data}

Adapun teknik pengumpulan data yang digunakan adalah pengumpulan data dapat dilakukan dengan berbagai sumber maupun cara. Dilihat dari sumber datanya, maka pengumpulan data dapat menggunakan sumber primer dan sumber sekunder. Sedangkan 
dilihat dari cara atau teknik pengumpulan data dapat dilakukan dengan kuesioner (angket) dan observasi (pengamatan).

\subsection{Metode Analisis Data}

Metode analisis data yang digunakan dalam penelitian ini adalah analisis regresi linier berganda (Multiple Regression Analysis) dengan bantuan program Statistical Product and Service Solution (SPSS). Analisis ini dimaksudkan untuk mengungkapkan pengaruh antara beberapa variabel bebas dengan variabel terikat. Variabel independen dalam penelitian ini adalah Komitmen Organisasi $\left(\mathrm{X}_{1}\right)$ dan Pengendalian Internal $\left(\mathrm{X}_{2}\right)$, dengan variabel dependen adalah Resiko Kecurangan dalam Pelaksanaan Jaminan Kesehatan (Y).

\section{HASIL ANALISIS DAN PEMBAHASAN}

\subsection{Hasil analisis}

Penelitian ini bertujuan untuk meneliti apakah terdapat pengaruh atas pengendalian internal dan komitmen organisasi dalam resiko fraud dalam pelaksanaan jaminan kesehatan. Objek dalam penelitian ini adalah pengendalian internal, komitmen organisasi, dan tingkat pencegahan fraud asuransi dan jaminan kesehatan. Variabel independen dalam penelitian ini adalah pengendalian internal dan komitmen organisasi. Sedangkan untuk variabel dependen dalam penelitian ini adalah pencegahan fraud jaminan kesehatan. Periode penelitian ini dilakukan pada tahun 2017. Subjek penelitian yaitu Rumah Sakit Bhayangkara Polda Sulut. Responden dalam penelitian ini tenaga medis dan karyawan yang bekerja di Rumah Sakit Bhayangkara Polda Sulut. Dari 50 kuesioner yang disebar, hanya 48 kuesioner yang kembali dan dapat diolah dalam penelitian ini. Sehingga jumlah responden yang menjadi sampel dalam penelitian inu sebanyak 48 responden. Untuk menjelaskan latar belakang responden yang menjadi sampel dalam penelitian ini, maka dibuatkan table deskripsi profil responden. Deskripsi profil responden terdiri dari jenis kelamin, usia, jenjang pendidikan dan lama bekerja.

\subsubsection{Analisis Statistik Deskriptif}

Statistik deskriptif adalah statistik yang digunakan untuk menganalisis data dengan cara mendeskripsikan atau memberikan gambaran data mengenai variabel-variabel penelitian (keahlian auditor, pengetahuan auditor, kompleksitas tugas dan audit judgment). Hasil statistik deskriptif dapat dilihat pada tabel 4.6 sebagai berikut :

Tabel 4.1

Statistik Deskriptif

\begin{tabular}{|l|l|r|r|c|r|}
\hline & N & Minimum & Maximum & Mean & Std. Deviation \\
\hline Komitmen Organisasi & 41 & 29.00 & 45.00 & 35.8049 & 4.31984 \\
Pengendalian Internal & 41 & 44.00 & 66.00 & 54.6341 & 7.21719 \\
Resiko Kecurangan & 41 & 19.00 & 34.00 & 26.4146 & 4.25427 \\
Valid N (listwise) & 41 & & & & \\
\hline
\end{tabular}

Sumber data: hasil olahan

Dari tabel 4.1, berdasarkan jawaban dari 41 responden maka hasil pengukuran variabel komitmen organisasi $\left(\mathrm{X}_{1}\right)$ diperoleh skor jawaban responden mempunyai rata-rata 35,80 dengan standar deviasi 4,391. Hasil pengukuran variabel pengendalian internal ( $\left.\mathrm{X}_{2}\right)$ mempunyai rata-rata 54,63 dengan standar deviasi 7,217. Hasil pengukuran variabel resiko kecurangan (Y) mempunyai rata-rata 26.41 dengan standar deviasi 4,254. 


\subsubsection{Hasil Uji Kualitas Data \\ 4.2.3.1 Uji Validitas}

Pengujian validitas dilakukan untuk mengetahui apakah alat ukur yang dirancang dalam bentuk kuesioner benar-benar dapat menjalankan fungsinya. Dalam pengujian validitas bertujuan untuk mengetahui apakah pernyataan yang telah diterapkan dalam kuesioner dapat mengukur variabel yang telah ada. Hasil uji validitas menunjukkan bahwa semua variabel memiliki nilai valid.

\subsubsection{Uji Reliabilitas}

Selain sebuah kuesioner harus valid, kuesioner juga harus reliabel. Cara pengukurannya adalah seluruh item pertanyaan yang telah valid dimasukkan dan diukur koefisien cronbach alpha. Jika nilai koefisien cronbach alpha $>0.6$ maka kuesioner tersebut telah reliabel. Hasil pengujian menunjukkan bahwa semua variabel menunjukkan hasil yang reliabel.

\subsubsection{Hasil Uji Asumsi Klasik \\ 4.2.4.1 Uji Normalitas}

Uji normalitas bertujuan untuk membuktikan bahwa data yang dipergunakan berdistribusi normal. Dasar pengambilan keputusan dalam uji normalitas yakni: jika nilai signifikansi lebih besar dari 0.05 maka data tersebut berdistribusi normal. Sebaliknya kurang dari 0.05 maka data tersebut tidak berdistribusi normal. Hasil pengujian menunjukkan bahwa distribusi error dari data terdistribusi dengan normal.

\subsubsection{Uji Multikolinieritas}

Uji ini bertujuan untuk menguji apakah dalam model regresi ditemukan adanya korelasi antara variabel-variabel bebas. Pada model regresi yang baik seharusnya tidak terjadi korelasi di antara variabel-variabel bebas. Dasar pengambilan keputusan, jika nilai tolerance $<0.10$ atau VIF $>10$ maka terjadi multikolinieritas sedangkan jika nilai tolerance $>0.10$ atau VIF $<10$ maka tidak terjadi multikolinieritas. Hasil pengujian menunjukkan bahwa antar variabel independen tidak terjadi efek multikolinearitas.

\subsubsection{Uji Heteroskedastisitas}

Uji heteroskdastisitas bertujuan untuk menguji apakah dari model regresi terjadi ketidaksamaan varians dari residual satu pengamatan ke pengamatan yang lain. Model regresi yang baik adalah yang homoskedastisitas atau tidak terjadi heteroskedastisitas. Salah satu cara untuk mendeteksi ada atau tidaknya heteroskedastisitas adalah dengan melihat grafik catterplot antara niai prediksi variabel terikat dengan residualnya. Jika pola tertentu, seperti titik-titik menyebar di atas dan di bawah angka 0 pada sumbu $Y$, maka tidak terjadi heteroskedastisitas.

\subsubsection{Analisis Regresi Linier Berganda}

Analisis regresi digunakan untuk mengetahui hubungan yang ada antara variabelvariabel sehingga dari hubungan yang diperoleh dapat ditaksir variabel yang satu, apabila harga variabel linnya diketahui. Persamaan model regresi yang digunakan penulis adalah persamaan regresi linear berganda.

\subsubsection{Uji Pengaruh Simultan (uji F)}

Pada penelitian ini, uji $\mathrm{F}$ digunakan untuk mengetahui apakah secara simultan koefisien variabel bebas mempunyai pengaruh nyata atau tidak terhadap variabel terikat. Dasar pengambilan keputusannya adalah dengan melihat nilai signifikansi. Apabila nilai sig < 
0,05 atau $\mathrm{F}$ hitung $>\mathrm{F}$ table maka terdapat pengaruh variabel $\mathrm{X}$ secara simultan terhadap variabel Y. sebaliknya, apabila nilai sig $>0,05$ atau $F$ hitung $<F$ tabel maka tidak terdapat pengaruh variabel $\mathrm{X}$ secara simultan terhadap variabel $\mathrm{Y}$. Hasil analisis Uji $\mathrm{F}$ diperoleh $\mathrm{F}_{\text {hitung }}$ $=5,697>\mathrm{F}_{\text {tabel }}=3,18$ dengan tingkat signifikansi adalah $0.006<0.05$. Hasil pengujian ini menunjukkan bahwa variabel komitmen organisasi $\left(X_{1}\right)$ dan pengendalian internal $\left(X_{2}\right)$ secara simultan terhadap resiko kecurangan dalam pelaksanaan jaminan kesehatan(Y).

\subsubsection{Uji Parsial (uji t)}

Pada penelitian ini, uji t digunakan untuk menguji apakah hipotesis yang diajukan dalam penelitian ini diterima atau tidak dengan mengetahui apakah variabel independen secara individual memengaruhi variabel dependen. Adapun metode dalam penentuan tabel menggunakan ketentuan tingkat signifikan 0,05 .

\begin{tabular}{|c|c|c|c|c|c|}
\hline \multirow[t]{2}{*}{ Model } & \multicolumn{2}{|c|}{$\begin{array}{c}\text { Unstandardized } \\
\text { Coefficients }\end{array}$} & $\begin{array}{l}\text { Standardized } \\
\text { Coefficients }\end{array}$ & \multirow[t]{2}{*}{$\mathrm{t}$} & \multirow[t]{2}{*}{ Sig. } \\
\hline & $\mathrm{B}$ & Std. Error & Beta & & \\
\hline (Constant) & 35.137 & 13.394 & & 2.623 & .012 \\
\hline 1 komitmen organisasi & -1.128 & .355 & -.506 & -3.176 & .003 \\
\hline pengendalian internal & .841 & .312 & .429 & 2.696 & .010 \\
\hline
\end{tabular}

\subsubsection{Uji Koefisien Determinasi}

\section{Tabel 4.2}

Hasil Koefisien Determinasi

\begin{tabular}{|c|r|r|r|r|}
\hline Model & \multicolumn{1}{|c|}{ R } & R Square & Adjusted R Square & $\begin{array}{c}\text { Std. Error of the } \\
\text { Estimate }\end{array}$ \\
\hline 1 & $.449^{\mathrm{a}}$ & .202 & .167 & 7.566 \\
\hline
\end{tabular}

a. Predictors: (Constant), pengendalian internal, komitmen organisasi

Sumber data: hasil olahan

Berdasarkan tampilan output model summary pada tabel 4.2 besarnya R Square (koefisien determinasi yang telah disesuaikan) adalah 0.202 , nilai ini menunjukkan bahwa $20.2 \%$. Artinya pengaruh variabel komitmen organisasi dan pengendalian internal terhadap variabel resiko kecurangan sebesar 20,2\%. sedangkan sisanya79.8\% dipengaruhi oleh variabel lain yang tidak diteliti dalam penelitian ini.

\subsection{Pembahasan}

\subsubsection{Pengaruh Komitmen Organisasi terhadap Resiko Kecurangan dalam} pelaksanaan Jaminan Kesehatan

Berdasarkan hasil uji t, maka dapat disimpulkan hipotesis Ho1 ditolak dan Ha1 diterima. Hal ini menunjukkan komitmen organisasi berpengaruh terhadap resiko kecurangan dalam pelaksanaan jaminan kesehatan. Nilai Minus yang didapatkan pada $t$ hitung diabaikan karena tidak menjadi masalah selama $\mathrm{X}_{1}$ tidak sama dengan 0 dan uji regresi lainnya seperti data sudah terdistribusi dengan normal, tidak terjadi heteroskedastisitas, tidak terjadi multikolinieritas sudah terpenuhi.

\subsubsection{Pengaruh Pengendalian Internal terhadap Resiko Kecurangan dalam pelaksanaan Jaminan Kesehatan}


Berdasarkan hasil uji t, maka dapat disimpulkan hipotesis Ho1 ditolak dan Ha1 diterima. Hal ini menunjukkan bahwa pengendalian internal akan mempengaruhi resiko kecurangan secara signifikan. Hasil penelitian menunjukkan bahwa pernyataan responden terhadap pengendalian internal dan resiko kecurangan pada Rumah Sakit Bhyangkara dalam kategori sangat baik. Hal ini menunjukkan bahwa pengendalian internal di rumah sakit aktivitasnya seperti lingkungan pengendalian, penilaian resiko, informasi dan komunikasi, aktivitas pengendalian dan pemantauan telah diterapkan dan berjalan dengan baik.

\section{KESIMPULAN DAN SARAN}

\subsection{Kesimpulan}

Berdasarkan hasil uji hipotesis yang telah dilakukan, maka dapat disimpulkan bahwa:

a. Komitmen Organisasi $\left(\mathrm{X}_{1}\right)$ berpengaruh terhadap resiko kecurangan dalam pelaksanaan jaminan kesehatan (Y), sehingga hipotesis pertama diterima. Hasil penelitian ini sejalan dengan penelitian yang dilakukan Ni Putu Sri Widiutami (2017). Hasil penelitian ini menunjukkan semakin tingginya rasa komitmen organisasi yang dimilki maka dapat mencegah resiko terjadinya kecurangan dalam pelaksanaan jaminan kesehatan.

b. Pengendalian Internal $\left(\mathrm{X}_{2}\right)$ berpengaruh terhadap resiko kecurangan dalam pelaksanaan jaminan kesehatan (Y), sehingga hipotesis kedua diterima. Penelitian ini sejalan dengan penelitian Anggit Purwitasari (2013). Hal ini menunjukkan bahwa pengendalian internal di rumah sakit telah menjalankan aktivitasnya seperti lingkungan pengendalian, penilain resiko, informasi dan komunikasi, aktivitas pengendalian dan pemantauan telah diterapkan dan berjalan dengan baik. Sehingga dengan kelima aktivitas pengendalian internal diatas dapat mencegah resiko kecurangan terjadi dalam pelaksanaan jaminan kesehatan.

c. Komitmen organisasi $\left(\mathrm{X}_{1)}\right.$ dan pengendalian internal $\left(\mathrm{X}_{2}\right)$ secara simultan terhadap resiko kecurangan dalam pelaksanaan jaminan kesehatan(Y). Dengan menanamkan rasa komitmen penuh terhadap organisasi dan menekankan pada keefektifan pengendalian internal dan kekuatan pada lingkungan pengendalian, maka hal tersebut dapat mengatasi resiko terjadinya fraud dalam pelaksanaan jaminan kesehatan. Disamping itu, dengan menanamkan komitmen organisasi disuatu unit kerja dengan memiliki mental/pendirian yang kokoh dan konsekuen serta memiliki kemampuan untuk menghilangkan timbulnya perilaku curang, melalui proses penegakkan kedisiplinan dan adanya kepatuhan dari karyawan dan tenaga medis serta prosesnya harus transparan dan dapat dinilai dengan aturan berlaku yang ada akan bebas dari pengaruh kecurangan.

\subsection{Saran}

Berdasarkan keterbatasan-keterbatasan yang ada dalam penelitian ini, berikut beberapa saran yang diberikan:

1. Bagi Rumah Sakit yang menjadi subjek dalam penelitian ini.

Berdasarkan hasil penelitian menunjukan adanya pengaruh pengendalian internal dan komitmen organisasi terhadap pencegahan fraud pengadaan barang. Berdasarkan hasil tersebut, diharapkan pihak manajemen rumah sakit lebih memperhatikan lagi dalam menerapkan implementasi pengendalian internal di rumah sakit, serta disarankan agar manajemen rumah sakit mampu menanamkan rasa komitmen terhadap organisasi kepada setiap karyawan. Dengan adanya kedua faktor tersebut, kemungkinan akan mampu mencegah resiko kecurangan terjadi dalam pelaksanaan jaminan kesehatan di rumah sakit.

2. Bagi Peneliti Selanjutnya 
a. Diharapkan untuk peneliti selanjutnya tidak terpaku pada kedua faktor dalam penelitian ini yaitu komitmen organisasi dan pengendalian internal namun dapat menambah faktor-faktor lain yang mungkin dapat mempengaruhi resiko terjadinya kecurangan dalam pelaksanaan jaminan kesehatan.

b. Agar hasil penelitian ini dapat digunakan secara dan luas, maka untuk

peneliti berikutnya subjek penelitian juga tidak hanya terbatas pada rumah sakit yang menjadi subjek dalam penelitian ini, namun mungkin dapat menambah rumah sakit lainnya sebagai subjek penelitian atau mungkin subjek penelitian dapat diganti dengan perusahaan manufaktur misalnya. Sehingga hasil penelitiannya pun dapat menggambarkan dapat menggambarkan secara umum dan luas, mengenai faktorfaktor yang dapat mencegah resiko terjadinya kecurangan dalam pelaksanaan jaminan kesehatan.

\section{DAFTAR PUSTAKA}

Amin, Widjaya Tunggal. 2014. Mendeteksi Kecurangan Dalam Akuntansi. Jakarta: Harvarindo.

Anggit, Purwitasari. 2013. Pengaruh Pengendalian Internal dan Komitmen Organisasi dalam pencegahan fraud pengadaan barang. Skripsi. Universitas Widyatama.

Baker, C Richard et al. 2016. Consideration Beyond the Fraud Triangle in the Fradu at Societe Generale. Journal of forensic and investigative accounting volume 8: issue 3 July-December 2016. France.

COSO, 2013, Internal Control - Integrated Framework : Executive Summary, Durham, North Carolina, May 2013. Dikutip 27 April 2017

Dina, Rizkyana et al. 2015. Pengaruh Audit Internal dan Audit Eksternal Terhadap Pencegahan Fraud. Skripsi. Universitas Islam Bandung.

Dordevic, Milica and Tadija Dukic. 2015. Contribution of internal audit in the fight against fraud. Economic and organization Vol. 12 No. 4, 2015. University Of Nis, Serbia

Ghozali, Imam. 2013. Aplikasi analisis multivariate dengan program IBM SPSS 21. Edisi Tujuh. Semarang: Universitas Diponegoro

Gusti, Ayu Kentut Rencana Sari Dewi. 2016. Pengaruh Moralitas Individu Dan Pengendalian Internal Pada Kecurangan Akuntansi. Jurnal Ilmiah Akuntansi, Vol. 1, No. 1, Hal: 7792, Juni 2016. Universitas Ganesha

Hansen, Don R dan Maryanne M. Mowen. 2015. Akuntansi Manajerial. Penerbit Salemba Empat. Jakarta Selatan

Kadek, Anggun Kusuma Dewi. 2017. Pengaruh Pengendalian Intern Kas, Moralitas Individu, Gaya Kepemimpinan dan Kepauasan Kerja Terhadap Kecenderungan Terjadinya Kecurangan (Fraud) Kas. E-Jurnal Akuntansi Program (Vol: 7 No:1 Tahun 2017). Universitas Ganesha

Karyono, 2013. Forensic Fraud. Yogyakarta: C.V Andi

Kulikova, I.I and D.R. Satdarova. 2016. Internal control dan compliance control as effective methords of management detection and prevention of financial statement fraud. Academy of strategic management journal Volume 15, Special issues 1, 2016. Kazan Federal University 